\title{
IGCP-640, S4SLIDE Significance of modern and ancient Subaqueous Slope landSLIDEs: current and future activities
}

\author{
Lorena Moscardelli* \\ The University of Texas at Austin, Statoil RDI Austin, Texas, USA; S4SLIDE Project Leader; *Corresponding author, \\ E-mail: lorena.moscardelli@utexas.edu
}

\section{Background}

The S4SLIDE project (IGCP-640) builds upon the extremely successful E-MARSHAL and IGCP-511 projects also known as the Submarine Mass Movements and Their Consequences project. S4SLIDE has a broader reach that seeks to incorporate learnings from lacustrine, coastal and subaerial landslides. As with its predecessors, the IGCP-640 project focuses on facilitating the interaction of scientists, engineers, industry and government representatives, and other parties interested in subaqueous mass movements and their geohazard potential. More information about IGCP-640 scope and activities can be obtain visiting the S4SLIDE webpage and by following us in Twitter.

Webpage: https://sites.google.com/a/utexas.edu/s4slide/home

Twitter account: @S4SLIDE

\section{Reporting on S4SLIDE Activities - 2016/2017}

A series of activities were conducted during 2016 that are summarized here:

\section{$12^{\text {th }}$ International Symposium on Landslides in Naples (12-19 June 2016)}

S4SLIDE Session: Comparing and bridging the gap between subaerial and subaqueous mass movement's processes and concepts

Co-Chairs: Dr. Aggeliki Georgiopoulou from University College Dublin and Dr. Jacques Locat from Université Laval

During this session, S4SLIDE grantee Dr. Agostino Meo from the University of Sannio presented his work on the "Kinematics and the tsunamigenic potential of the Taranto Landslide (northeastern Ionian Sea): Morphological Analysis and Modeling." Presenters and attendees discussed the importance of characterizing subaqueous landslides in lakes, fjords and other coastal areas, as well as the need to understand in more detail the nature of the transition between subaerial and subaqueous landslides (a topic that is also relevant for lacustrine basins).

\section{$35^{\text {th }}$ International Geological Congress in Cape Town (27 August-4 September 2016)}

S4SLIDE Session: "Subaerial and submarine landslide processes and hazards"

Co-Chairs: Dr. Aaron Micallef from the University of Malta, Dr.
Claudio Lo Iacono from the National Oceanography Centre, Dr. Stefan Grab from the University of the Witwatersrand and Dr. Mauro Soldati from the Universitá di Modena e Reggio Emilia in conjunction with the International Association of Geomorphologists.

The most interesting topic focused on the issue of landslide monitoring, with scientists who worked in terrestrial settings sharing their experiences and providing useful insights to their colleagues working in subaqueous environments. Thirty-three presenters from thirteen countries made technical contributions to this S4SLIDE session in Cape Town. In addition, Dr. Aaron Micallef and Dr. Graham Nickerson from Highland Geo Solutions taught a short course during the conference on the topic of "Seafloor Exploration and Surveying Techniques for the Earth Sciences: The State-of-the-Art."

\section{International Symposium on Marine Engineering Geol- ogy ISMEG2016 in Qingdao (21-24 October 2016)}

S4SLIDE Sessions: "Regional Engineering Geology and Offshore Hazards" and "Marine Engineering Geological Survey Technology and Data Analysis."

Co-Chairs: Dr. Roger Urgeles from the Institut de Ciències del Mar and Dr. Maarten Vanneste from the Norwegian Geotechnical Institute

This symposium aimed at addressing issues associated with engi-

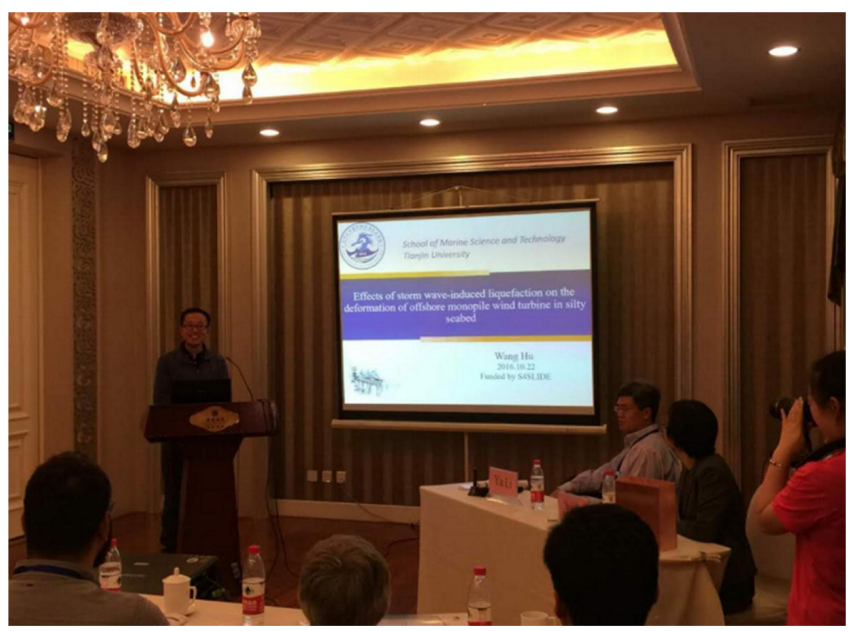

Figure 1. S4SLIDE grantees Wangcheng Zhang and Wang Hu presented their work at the 2016 International Symposium on Marine Engineering Geology congress in Qingdao, China (21-24 October). In the picture, Wang Hu presenting his work on the "Effects of storm wave-induced liquefaction on the deformation of offshore monopole wind turbine in silty seabed". 
neering geological problems associated with the increasing exploitation of oil and gas, the development of ports, submarine communication infrastructure and coastal reclamation. Two S4SLIDE grantees presented their work during the conference, Wangcheng Zhang from the University of Western Australia and Wang Hu from Tianjin University (Fig. 1).

ECORD Summer School: Submarine Geohazards: Mapping, Monitoring, and Modelling in Germany (5-16 September 2016)

S4SLIDE also co-sponsored the ECORD summer school that took place in the MARUM Center for Marine Environmental Sciences and the IODP Bremen Core Repository in Germany. The main objective of the ECORD summer school is to bring $\mathrm{PhD}$ students and young postdocs in touch with IODP at an early stage of their careers so that they can be informed about the many opportunities associated with these projects.

\section{$I^{\text {st }}$ S4SLIDE Workshop on Subaqueous Landslides and Morphometric Parameters in London (23-24 January 2017)}

Organizers: Dr. Mike Clare from the National Oceanography Center of Southampton and Dr. Christopher Jackson from Imperial College of London.

S4SLIDE started 2017 with a workshop that took place in London during the month of January. The aim of this workshop was to continue our community effort to advance the understanding of subaqueous landslides based on the collection of morphometric parameters. This is a long term and complex effort that requires consensus within the community in terms of how to define measurement criteria, agreement on meaning of morphometric relationships and the design of an effective and versatile delivery platform. This effort will continue during the current year (Fig. 2).

\section{American Association of Petroleum Geologists Annual Meeting in Houston (2-5 April 2017)}

S4SLIDE Session: "Non-turbidite deepwater units as key petroleum system elements"

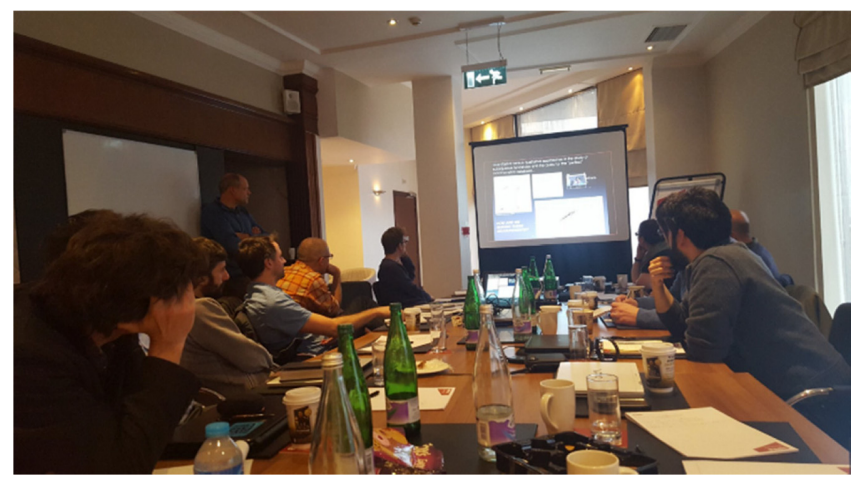

Figure 2. Researchers meet in London to discuss how to define and measure subaqueous landslide morphometric parameters. The meeting also served as a platform to discuss strategies for the creation of a global subaqueous landslide morphometric database.

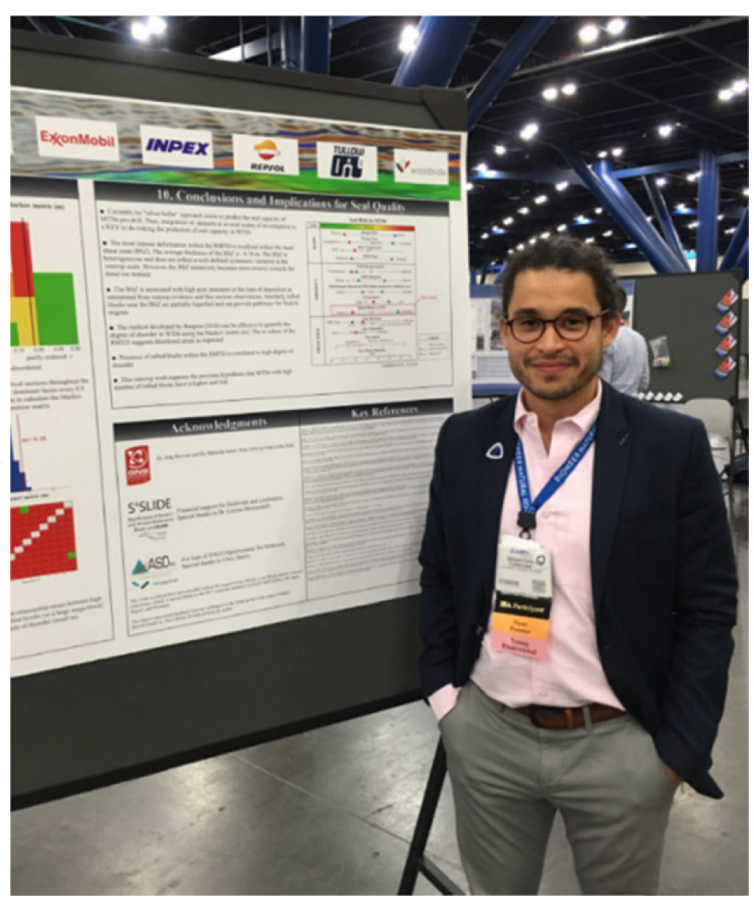

Figure 3. PhD candidates Hang Deng and Sebastian Cardona from Colorado School of Mines presented their posters during the AAPG Centennial in Houston, Texas. Hang Deng presented his work on the "Influence of Topography on Subaqueous Sediment Gravity Flows and the Resultant Deposits: Examples from Deep-water Systems in Offshore Trinidad". Sebastian Cardona presented current work on "Macroscopic to Microscopic Criteria for Assessing Spatial Changes in Material and Bounding Surface Character of Mass-Transport Deposits and Implications for Seal Quality".

Co-Chairs: Dr. Derek Sawyer from The Ohio State University, Dr. Kei Ogata from University of Amsterdam and Dr. Javier HernándezMolina from Royal Holloway

The American Association of Petroleum Geologists (AAPG) celebrated its centennial in Houston. The S4SLIDE session intended to focus attention into non-turbidite deposits within deep-water basins and to discuss their importance within the context of oil and gas exploration activities. A follow-up discussion was held in Houston where aspects associated with the economic importance of both submarine mass movements and non-turbidite deposits in general were addressed. Two S4SLIDE grantees from Colorado School of Mines presented posters during the conference (Fig. 3).

\section{European Geosciences Union in Vienna (23-28 April 2017)}

S4SLIDE Session: "Submarine landslide hazard and marine paleoseismology: regional and global implications" and "Processes and products of deltas, submarine fans and subaquatic sediment gravity flows"

Co-Chairs: Dr. Oded Katz from the Geological Survey of Israel and Dr. Michael Strasser from University of Innsbruck

Three S4SLIDE grantees presented their work as part of EGU 2017 covering a wide range of topics including post-eruptive submarine processes, causal mechanisms of submarine landslides, as well as 


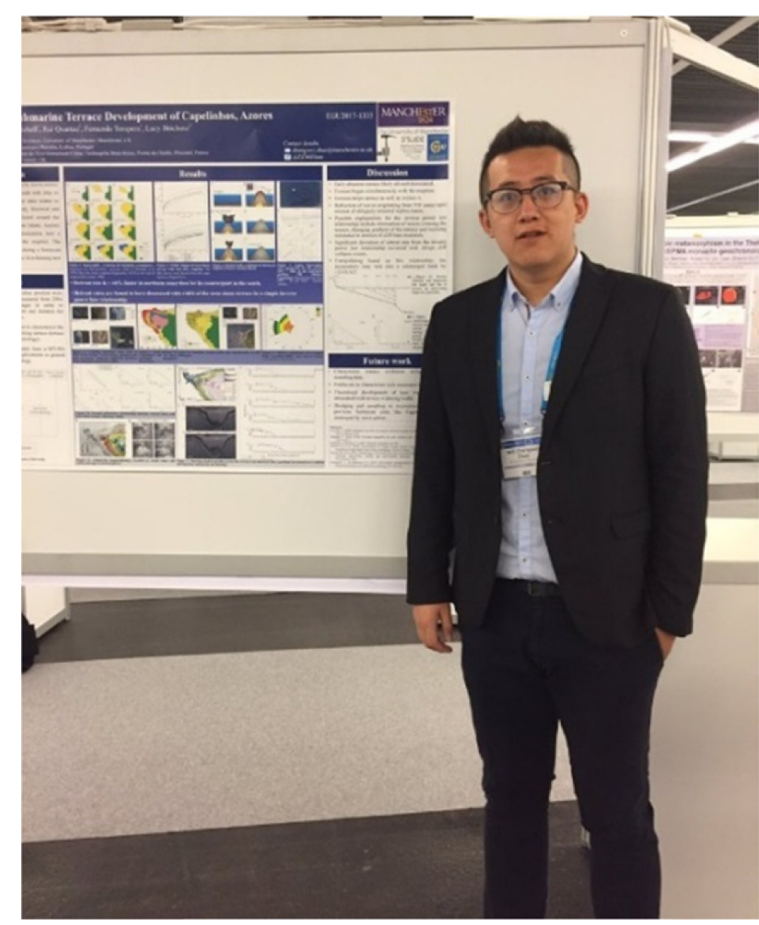

Figure 4. PhD candidate Will Zhongwei Zhao from the University of Manchester presented his work on "Post-eruptive Submarine Terrace Development of Capelinhos, Azores" as part of EGU 2017. Other S4SLIDE grantees included: Dr. Benjamin Bellwald from the University of Bergen who presented work on "The Role of Overpressure and Seismic Activity for the Generation of the Tampen Slide, North Sea Trough Mouth Fan". And Dr. Kamal'Deen Olakunle Omosanya who presented work on the "Facies Architecture and Compositional Variations of Coves Associated with Recurrent Mass Wasting in the Norwegian North Sea”.

facies architectures and compositional variations associated with the recurrence of mass wasting events (Fig. 4).

\section{Future S4SLIDE Activities - 2017 and Beyond}

\section{EVAN Conference in Southampton (5-8 September 2017)}

S4SLIDE Session: Statistics of Natural Hazards Hackathon Chair: Dr. Mike Clare from the National Oceanography Centre

This session will take place during a practical and informal day
(September 8th) to share ideas and statistical approaches by working on real data, learn from multiple disciplines, spin up new collaborations, and to analyze real natural hazards data to try and answer key questions. Any datasets are welcomed, ranging from incomplete, small sample size and disparately-sourced through to "Big Data" and that concern any aspect of natural hazards (e.g., controls/forcing, probability, magnitude, impact, risk etc.).

\section{Geological Society of America Annual Meeting in Seat- tle (22-25 October)}

S4SLIDE Session: T230: Polygenetic Melanges: A Glimpse on Tectono-Sedimentary Recycling in Convergent Margins

Co-Chairs: Andrea Festa from Universitá degli Studi di Torino, Kei Ogata from Vrije Universiteit and Gian Andrea Pini from Universitá degli Studi di Trieste

This session addresses the definition of structures, fabric, and texture diagnostic of sedimentary mélanges overprinted by other processes and the estimation of their occurrence in fossil, exhumed, and present-day accretionary wedges and collisional chains.

\section{$9^{\text {th }}$ International Conference in Geomorphology in Vig- yan Bhawan (6-11 November 2017)}

S4SLIDE Session: Submarine Geomorphology

Co-Chairs: Dr. Aaron Micallef from the University of Malta, Dr. Sebastian Krastel from GEOMAR and Dr. Alessandra Savini from Milano-Bicocca University

This session aims to examine the causes and consequences of geomorphic and tectonic processes shaping underwater landscapes, including submarine erosion and depositional processes, submarine landslides, sediment transfer and deformation, volcanic activity, fluid migration and escape, faulting and folding

\section{$8^{\text {th }}$ International Symposium on Submarine Mass Move- ments and Their Consequences (7-8 May, 2018)}

Conveners: Dr. Dave Mosher from the University of New Hampshire and Dr. Gwyn Lintern from the Geological Survey of Canada

S4SLIDE is currently accepting grant applications for students and young researchers to cover partial cost to attend and participate in all these events. Details regarding grant information can be found in the S4SLIDE webpage: https://sites.google.com/a/utexas.edu/s4slide/ 